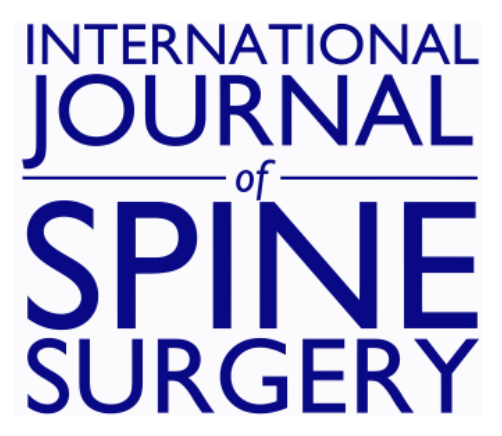

\title{
Fusing to the Sacrum/Pelvis: Does the Risk of Reoperation in Thoracolumbar Fusions Depend on Upper Instrumented Vertebrae (UIV) Selection?
}

Uchechi Iweala, Jack Zhong, Caroline Varlotta, Roee Ber, Laviel Fernandez, Eaman Balouch, Yong Kim, Themistocles Protopsaltis and Aaron J. Buckland

Int J Spine Surg 2021, 15 (5) 953-961

doi: https://doi.org/10.14444/8125

http://ijssurgery.com/content/15/5/953

This information is current as of April 26, 2023.

Email Alerts Receive free email-alerts when new articles cite this article. Sign up at:

http://ijssurgery.com/alerts

The International Journal of Spine Surgery

2397 Waterbury Circle, Suite 1,

Aurora, IL 60504, Phone: +1-630-375-1432 


\title{
Fusing to the Sacrum/Pelvis: Does the Risk of Reoperation in Thoracolumbar Fusions Depend on Upper Instrumented Vertebrae (UIV) Selection?
}

\author{
UCHECHI IWEALA, MD, MBA, JACK ZHONG, MD, CAROLINE VARLOTTA, MD, ROEE BER, MD, \\ LAVIEL FERNANDEZ, MD, EAMAN BALOUCH, MD, PhD, YONG KIM, MD, THEMISTOCLES \\ PROTOPSALTIS, MD, AARON J. BUCKLAND, MBBS, FRACS, FAOrthA \\ Division of Spine, Department of Orthopedic Surgery, New York University Langone Health, New York City, NY
}

\begin{abstract}
Background: There is controversy as to whether fusions should have the upper instrumented vertebrae (UIV) end in the upper lumbar spine or cross the thoracolumbar junction. This study compares outcomes and reoperation rates for thoracolumbar fusions to the sacrum or pelvis with UIV in the lower thoracic versus lumbar spine to determine if there is an increased reoperation rate depending on UIV selection.

Methods: A retrospective review of prospectively collected data was conducted from a single-center database on adult patients with degeneration and deformity who underwent primary and revision fusions with a caudal level of S1 or ilium between 2012 and 2018. Fusions were classified as anterior, posterior, or combination approach. Revision fusions included patients who had spinal surgery at another institution prior to their revision surgery at the center. Patients were categorized into 1 of 3 groups based on UIV: T9-T11, upper lumbar region (L1-L2), and lower lumbar region (L3-L5). Inclusion criteria were age 18 years or older and at least 1 year of clinical follow-up. Patients were excluded from analysis if they had tumors, infections, or less than 1 year of follow-up after the index procedure.

Results: The reoperation rates for the UIV groups in the thoracic $(28 \%)$ and upper lumbar $(27 \%)$ spine were nearly equal in magnitude and were both significantly higher than the reoperation rate in the lower lumbar group (18\%, $P=.046)$. Reoperation for the diagnosis of adjacent segment disease was $8.3 \%$ in the upper lumbar spine and statistically significantly higher than the reoperation rates for adjacent segment disease in the thoracic $(1 \%)$ or lower lumbar $(4.5 \%, P=.042)$ spine. Reoperations for pseudoarthrosis and proximal junctional kyphosis were $13 \%$ and $4 \%$, respectively, in the thoracic spine, both of which were statistically significantly different (pseudoarthrosis, $P=.035$; proximal junctional kyphosis, $P=.002$ ) from the reoperation rates for the same diagnoses in the upper lumbar spine $(4.6 \%$ and $1 \%)$ or lower lumbar spine $(6.2 \%$ and $0 \%)$. A multivariate logistical regression model at 2-year follow up did not show a statistically significant difference between reoperation rates between the thoracic and upper lumbar spine UIV groups.

Conclusion: Constructs with UIV in the thoracic spine suffer from higher rates of proximal junctional kyphosis and pseudoarthrosis, whereas those with UIV in the upper lumbar spine have higher rates of adjacent segment disease. Given this tradeoff, there is no certain recommendation on what UIV will result in a lower reoperation rate in thoracolumbar fusion constructs to the sacrum or pelvis. Surgeons must evaluate patient characteristics and risks to make the optimal decision.

Lumbar Spine
\end{abstract}

\section{INTRODUCTION}

Spinal fusion is commonly used for the treatment of degenerative spinal pathologies. The objective of a fusion is to provide neurologic decompression and stabilize the spine, with the aim of reducing disability and pain. Postoperative biomechanical changes are likely to play an important role in the pathogenesis of adjacent segment disease. Reducing motion across a fused segment increases stress on adjacent unfused spinal segments, which may accelerate degeneration of these adjacent unfused segments. ${ }^{1}$ This increased stress is thought to be particularly high when fusions have upper instrumented vertebrae (UIV) that end at or just below the thoracolumbar junction (eg, T12 or L1), which serves as a transition point between a rigid thoracic spine and mobile lower lumbar spine. Given this biomechanical inflection point, concerns have been raised for increased complications in multilevel lumbar spine instrumentation, specifically with constructs that have a lower instrumented vertebra 
(LIV) at the sacrum or pelvis and a UIV below the thoracolumbar junction. These complications include proximal junction kyphosis (PJK), proximal junctional fracture (PJF), and adjacent segment stenosis, all of which may require revision surgery. ${ }^{2}$

There are few previous studies supporting the notion that biomechanical complications and revision are less likely when the UIV crosses the thoracolumbar junction. ${ }^{2-4}$ However, when analyzing outcomes for lumbar fusion constructs to the sacrum or pelvis, Kim et $\mathrm{al}^{5}$ did not find a significant advantage to a UIV in the thoracic vertebrae vs the lumbar vertebrae regarding radiographs, clinical presentation, and revision rates. Thus, it is still unclear whether there are differences in outcomes for fusion constructs with LIV at the sacrum or pelvis and UIV in the lower thoracic spine versus upper lumbar spine. This study compares outcomes and reoperation rates of revision for thoracolumbar fusions to the sacrum or pelvis with UIV in the lower thoracic versus lumbar spine to determine if there is an increased revision rate depending on UIV selection.

\section{METHODS}

This was a retrospective study collected from a single-center database on adult patients with degeneration and deformities who underwent primary and revision fusions with a caudal level of S1 or ilium between 2012 and 2018. Fusions were classified as anterior approach, posterior approach, or a combination approach. Revision fusions included patients who had spinal surgery at another institution prior to their revision surgery at the center. Patients were categorized based on UIV into 3 groups: T9-T11, upper lumbar region (L1-L2), and lower lumbar region (L3L5). The UIV selection was determined according to the patient's underlying diagnosis, coronal and sagittal alignment, and presence or absence of degenerative changes, instability, or stenosis. There were no fixed criteria used for selection of UIV. Patients were included in the analysis if they were 18 years or older and had at least 1 year of clinical follow up. Patients with tumors, infections, or less than 1 year of followup after the index procedure were excluded from the analysis.

The primary analysis was a comparison of the 1and 2-year reoperation rates between each group. Chart review of each surgical case was used to determine the diagnoses that led to reoperation; adjacent segment disease, PJK, and pseudoarthrosis were isolated as variables of interest. The operative surgeon(s) of the index procedure determined the reoperation diagnoses as mentioned in clinical note or operative reports, but in general adjacent segment disease was defined as radiographic breakdown of cephalad or caudal level next to the instrumented construct; PJK was defined as a greater than $10^{\circ}$ increase in preoperative and postoperative sagittal cobb angle between the UIV and the UIV +1 ; and pseudoarthrosis was defined by lack of radiographic evidence of union at 12 months or otherwise radiographic evidence of nonunion (eg, broken hardware). Secondary analyses were the comparison of demographics, sagittal balance parameters, and intraoperative characteristics between each group. Demographic information included age, body mass index (BMI), comorbidities as measured by the Charleston Comorbidity Index (CCI), and diagnosis at primary surgery. Intraoperative factors considered were time, biologics use, blood loss, fluoroscopic use, and intraoperative complications. To determine if there was a difference in reoperation rates between primary and revision cohorts at 2year follow up, a multivariate logistical regression model was developed, with reoperation as the dependent variable and the primary or revision designation as an independent predictor. Demographic variables were also included in the regression as other independent predictors.

Statistical analysis was performed using SPSS v22 software (IBM Corporation, Chicago, IL). Chisquare and analysis of variance testing (ANOVA) were used to compare the cohorts. $P<.05$ was considered to be significant.

\section{RESULTS}

There were 498 total fusions that reached 1-year follow-up (Table 1). Of these, 99 patients had an UIV in the thoracic spine, 108 in the upper lumbar spine, and 291 in the lower lumbar spine. Average length of time to last follow-up was 2.5 years, and there was no statistically significant difference in follow-up time between groups. There were statistically significant differences between the groups for multiple demographic, intraoperative, postoperative, and reoperative factors.

There were a few demographic parameters that demonstrated statistically significant differences among UIV groups (Table 1). Older patients were on average more likely to have the UIV in the thoracic spine $(63.7 \pm 10.2)$, whereas younger patients were more likely to have the UIV in the lower lumbar 
Table 1. Upper instrumented vertebrae groups and associated demographics.

\begin{tabular}{|c|c|c|c|c|c|}
\hline Demographics & Thoracic (T9-T11) & Upper Lumbar (L1-L2) & Lower Lumbar (L3-L5) & Total & $P$ Value $^{\mathrm{a}}$ \\
\hline No. & 99 & 108 & 291 & 498 & \\
\hline Gender, No. ( $\%$ female $)$ & $67(67.7)$ & $64(59.3)$ & $153(52.6)$ & $284(57.0)$ & .102 \\
\hline Age, mean \pm SD, y & $63.7 \pm 10.2$ & $63.6 \pm 10.4$ & $54.6 \pm 13.9$ & $58.3 \pm 13.3$ & $<.001$ \\
\hline $\mathrm{BMI}$, mean $\pm \mathrm{SD}, \mathrm{kg} / \mathrm{m}^{2}$ & $28.7 \pm 6.4$ & $29.2 \pm 5.4$ & $29.5 \pm 6.7$ & $29.3 \pm 6.4$ & .609 \\
\hline $\mathrm{CCI}$, mean $\pm \mathrm{SD}$ & $2.4 \pm 1.7$ & $2.4 \pm 1.6$ & $1.7 \pm 1.8$ & $2.0 \pm 1.8$ & $<.001$ \\
\hline $\mathrm{ASA}$ grade, mean $\pm \mathrm{SD}$ & $2.5 \pm 0.5$ & $2.6 \pm 0.6$ & $2.2 \pm 0.6$ & $2.3 \pm 0.6$ & $<.001$ \\
\hline
\end{tabular}

Abbreviations: ASA, American Society of Anesthesiologists; BMI, body mass index; CCI, Charleston Comorbidity Index.

${ }^{a}$ Boldface indicates statistical significance.

spine (54.6 \pm 13.9). The CCI demonstrated a statistically significant difference $(P<.001)$. Higher CCI was observed in the thoracic $(2.4 \pm 1.7)$ and upper lumbar $(2.4 \pm 1.6)$ groups and was lowest in the lower lumbar group $(1.7 \pm 1.8)$. There was also a statistically significant difference in American Society of Anesthesiologists (ASA) grade $(P<.001)$ between the groups. The ASA grade was highest with the UIV in the upper lumbar region $(2.6 \pm 0.6)$ and lowest with the UIV in the lower lumbar region $(2.2 \pm 0.6)$. Of the demographic factors, there were no statically significant differences between the groups for sex or BMI.

The sagittal balance of each UIV group was assessed by subtracting lumbar lordosis (LL) from pelvic incidence (PI). Patients were deemed to have a PI-LL mismatch if PI-LL was more than $10^{\circ}$. There were 173 patients with baseline parameters, 140 patients with parameters at 1-year follow-up, 53 at 2-year follow-up, and 37 at last follow-up. There was a statistically significant difference in baseline PI-LL between the groups, with the thoracic UIV group having the largest average at $23^{\circ}$, followed by the upper lumbar UIV group at $21^{\circ}$, and finally the lower lumbar UIV group with the lowest average at $9^{\circ}$. At 1-year follow-up there was again a statistically significant difference in PI-LL, but the upper lumbar UIV group had the highest average at $21^{\circ}$, followed by the thoracic UIV group at $11^{\circ}$ and the lower lumbar UIV group at $7^{\circ}$. There was no statistically significant difference in PI-LL between the UIV groups at 2 or more years of follow-up. The results of the sagittal parameter measurements within each group are summarized in Table 2.

Four intraoperative factors demonstrated a statistically significant difference between the groups based on location of the UIV (Table 3). Operative time in minutes was longest in the thoracic UIV group (427.3 $\pm 152.0, P<.001)$ and shortest in the lower lumbar UIV group $(270.3 \pm 105.6, P<.001)$. Similarly, estimated blood loss (EBL in $\mathrm{mL}$ ) was highest in the thoracic UIV group $(2023.9 \pm 1303.4, P<.001)$ and lowest in the lower lumbar UIV group (499.7 \pm 541.2, $P<.001)$. Pelvic fixation rate was highest in the upper lumbar UIV group $(15.7 \%, P<.001)$ and lowest in the lower lumbar UIV group $(14.5 \%, P<.001)$. The index surgery was most likely to be a revision of a prior surgery in the T9-T11 region $(54.5 \%, P<.001)$ and least likely to be a revision of the lower lumbar region $(19.9 \%, P<.001)$. There were no statically significant differences between the groups for occurrence of intraoperative complication or durotomy.

Two postoperative factors (Table 3) displayed statistically significant differences between the UIV groups. Length of stay in days was shortest when the UIV was in the lower lumbar region $(3.8 \pm 2.1, P<$ $.001)$ and highest when the UIV was at T9-T11 (7.7 \pm 3.5, $P<.001)$. Postoperative complications showed an increasing prevalence with higher UIV $(P=.002)$. Table 4 presents a detailed summary of these complications. There were a total of 74 postoperative complications, with 22 complications

Table 2. Upper instrumented vertebrae groups and calculated pelvic incidence-lumbar lordosis (PI-LL, in degrees).

\begin{tabular}{|c|c|c|c|c|c|}
\hline PI-LL & Thoracic (T9-T11) & Upper Lumbar (L1-L2) & Lower Lumbar (L3-L5) & Total & $P$ Value $^{\mathrm{a}}$ \\
\hline Baseline, mean $\pm \mathrm{SD}$ & $23 \pm 17$ & $21 \pm 17$ & $9 \pm 15$ & $\overline{173}$ & $<.001$ \\
\hline No. & 33 & 22 & 118 & 173 & \\
\hline Year 1 , mean $\pm \mathrm{SD}$ & $11 \pm 13$ & $21 \pm 11$ & $7 \pm 13$ & - & .001 \\
\hline No. & 34 & 15 & 91 & 140 & \\
\hline Year 2, mean $\pm \mathrm{SD}$ & $3 \pm 12$ & $9 \pm 16$ & $11 \pm 14$ & - & .224 \\
\hline No. & 15 & 6 & 32 & 53 & \\
\hline Year 2 plus, mean \pm SD & $13 \pm 15$ & $13 \pm 11$ & $10 \pm 16$ & - & .788 \\
\hline No. & 9 & 9 & 19 & 37 & \\
\hline
\end{tabular}

${ }^{\mathrm{a} B o l d f a c e}$ indicates statistical significance. 
Table 3. Fusion from pelvis/sacrum to upper instrumented vertebrae group and associated surgical outcomes.

\begin{tabular}{|c|c|c|c|c|c|}
\hline & $\begin{array}{l}\text { Thoracic } \\
\text { (T9-T11) }\end{array}$ & $\begin{array}{l}\text { Upper Lumbar } \\
\text { (L1-L2) }\end{array}$ & $\begin{array}{l}\text { Lower Lumbar } \\
\text { (L3-L5) }\end{array}$ & Total & $P$ Value $^{\mathrm{a}}$ \\
\hline \multicolumn{6}{|l|}{ Intraoperative factors } \\
\hline Operative time, mean $\pm \mathrm{SD}$, min & $427.3 \pm 152.0$ & $345.1 \pm 134.3$ & $270.3 \pm 105.6$ & $317.4 \pm 137.0$ & $<.001$ \\
\hline Index surgery is revision of prior surgery, $\mathrm{n}(\%)$ & $54(54.5)$ & $51(47.2)$ & $58(19.9)$ & $163(32.7)$ & $<.001$ \\
\hline Intraoperative complication occurred, n $(\%)$ & $5(5.1)$ & $4(3.7)$ & $12(4.1)$ & $21(4.2)$ & .884 \\
\hline Intraoperative durotomy occurred, n (\%) & $5(5.1)$ & $5(4.6)$ & $9(3.1)$ & $19(3.8)$ & .6 \\
\hline Estimated blood loss, mean $\pm \mathrm{SD}, \mathrm{mL}$ & $2024 \pm 1303$ & $1072 \pm 981$ & $500 \pm 541$ & $916 \pm 1024$ & $<.001$ \\
\hline Pelvic fixation rate, $\mathrm{n}(\%)$ & $48(48.5)$ & $17(15.7)$ & $7(2.4)$ & $72(14.5)$ & $<.001$ \\
\hline \multicolumn{6}{|l|}{ Postoperative factors } \\
\hline Length of stay, mean $\pm \mathrm{SD}, \mathrm{d}$ & $7.7 \pm 3.5$ & $6.0 \pm 3.2$ & $3.8 \pm 2.1$ & $5.0 \pm 3.1$ & $<.001$ \\
\hline Postoperative complications within $90 \mathrm{~d}, \mathrm{n}(\%)$ & $22(22.2)$ & $14(13.0)$ & $38(13.0)$ & $76(15.3)$ & .38 \\
\hline Pulmonary complication postoperative, n (\%) & $3(3.0)$ & $2(1.9)$ & $1(0.3)$ & $6(1.2)$ & .084 \\
\hline Neurologic complication postoperative, n (\%) & $2(2.0)$ & $0(0.0)$ & $4(1.4)$ & $6(1.2)$ & .379 \\
\hline
\end{tabular}

${ }^{a}$ Boldface indicates statistical significance.

$(26.3 \%)$ in the thoracic UIV group, 14 complications $(13.0 \%)$ in the upper lumbar UIV group, and 38 complications $(13.0 \%)$ in the lower lumbar UIV group. Table 4 lists these complications by group. Cardiac complication was the only category that had a statistically significant difference between the groups. There were no complications in any group due to deep vein thrombosis or pulmonary embolism.

The reoperation rates at last follow-up for the UIV groups in the thoracic and upper lumbar spine were nearly equivalent, at approximately $28 \%$ and $27 \%$, respectively (Table 5). These reoperation rates were significantly higher than that of the lower lumbar group $(18 \%, P=.046)$. Reoperation for the diagnosis of adjacent segment disease did reveal a statistically significant difference between the upper lumbar $(8.3 \%, P=.042)$ and the thoracic $(1 \%)$ or lower lumbar $(4.5 \%)$ groups. Likewise, there was a statistically significant difference between the groups for reoperation for pseudoarthrosis $(P=$ $.035)$ and PJK $(P=.002)$, with the thoracic spine group having the highest rates at $13 \%$ and $4 \%$, respectively, compared with $4.6 \%$ and $1 \%$ for the upper lumbar spine and $6.2 \%$ and $0 \%$ for the lower lumbar spine. No statistically significant differences were observed between the groups for days to reoperation at last follow-up.

The multivariate logistical regression model of patient with 2-year follow-up did not show a statistically significant difference in reoperation rates between patients with a UIV in the thoracic or upper lumbar spine. Likewise, there was not a statistically significant difference in likelihood of reoperation between primary and revision lumbar fusion groups (Table 6). The results demonstrated a decreased likelihood of reoperation in older patients (odds ratio, 0.904). Of note, approach type (eg, anterior, posterior, or combination) did not have a statistically significant impact on the likelihood of reoperation. To further characterize differences between the 3 groups (thoracic, upper lumbar, lower lumbar), post hoc Tukey analysis was performed. The Appendix lists multiple tables showing the post hoc Tukey analysis for the variables tested.

\section{DISCUSSION}

There is currently no consensus as to whether there is an advantage to stopping a fusion in the

Table 4. Number of postoperative complications and complication rates in each upper instrumented vertebrae group.

\begin{tabular}{|c|c|c|c|c|c|}
\hline & $\begin{array}{c}\text { Thoracic (T9-T11), } \\
\text { No. (\%) }\end{array}$ & $\begin{array}{c}\text { Upper Lumbar (L1-L2), } \\
\text { No. }(\%)\end{array}$ & $\begin{array}{c}\text { Lower Lumbar (L3-L5), } \\
\text { No. }(\%)\end{array}$ & $\begin{array}{c}\text { Total, } \\
\text { No. }(\%)\end{array}$ & $P$ Value \\
\hline Postoperative complications & $22(22)$ & $14(13)$ & $38(13)$ & $74(15)$ & .002 \\
\hline Neurologic complications & $2(2)$ & $1(1)$ & $3(1)$ & $6(1)$ & .586 \\
\hline Cardiac complications & $7(7)$ & $2(2)$ & $5(2)$ & $14(3)$ & .009 \\
\hline $\mathrm{DVT} / \mathrm{PE}$ & $0(0)$ & $0(0)$ & $0(0)$ & $0(0)$ & - \\
\hline Pulmonary complications & $3(3)$ & $1(1)$ & $2(1)$ & $6(1)$ & .119 \\
\hline Airway edema & $0(0)$ & $0(0)$ & $1(0)$ & $1(0)$ & - \\
\hline Ileus & $4(4)$ & $3(3)$ & $6(2)$ & $13(3)$ & .176 \\
\hline Urinary complications & $1(1)$ & $3(3)$ & $8(3)$ & $12(2)$ & .253 \\
\hline Superficial infection & $2(2)$ & $0(0)$ & $3(1)$ & $5(1)$ & .661 \\
\hline Deep infection & $1(1)$ & $0(0)$ & $2(1)$ & $3(1)$ & .661 \\
\hline
\end{tabular}

Abbreviation: DVT, deep vein thrombosis; PE, pulmonary embolism.

${ }^{a}$ Boldface indicates statistical significance. 
Table 5. Fusion from pelvis/sacrum to upper instrumented vertebrae group and associated reoperation rates.

\begin{tabular}{|c|c|c|c|c|c|}
\hline Reoperation Factors & $\begin{array}{c}\text { Thoracic } \\
\text { (T9-T11) }\end{array}$ & $\begin{array}{l}\text { Upper Lumbar } \\
\text { (L1-L2) }\end{array}$ & $\begin{array}{l}\text { Lower Lumbar } \\
\text { (L3-L5) }\end{array}$ & Total, n (\%) & $P$ Value $^{\mathrm{a}}$ \\
\hline Reoperation rate at $1-\mathrm{y}$ FU, n $(\%)$ & $12(12.1)$ & $11(10.2)$ & $17(5.8)$ & $40(8.0)$ & .09 \\
\hline Reoperation rate at year $2 \mathrm{FU}, \mathrm{n}(\%)$ & $23(23.2)$ & $20(18.5)$ & $39(13.4)$ & $82(16.5)$ & .06 \\
\hline Reoperation rate at last FU, n $(\%)$ & $28(28.3)$ & $29(26.9)$ & $53(18.2)$ & $110(22.1)$ & .046 \\
\hline Days to reoperation, mean $\pm \mathrm{SD}$ & $456.8 \pm 373.0$ & $512.0 \pm 407.6$ & $544.2 \pm 455.2$ & $513.5 \pm 421.0$ & .677 \\
\hline Reoperation for adjacent segment disease, $\mathrm{n}(\%)$ & $1(1.0)$ & $9(8.3)$ & $13(4.5)$ & $23(4.6)$ & .042 \\
\hline Reoperation for proximal junctional kyphosis, $\mathrm{n}(\%)$ & $4(4.0)$ & $1(0.9)$ & $0(0.0)$ & $5(1.0)$ & .002 \\
\hline Reoperation for pseudoarthrosis, $\mathrm{n}(\%)$ & $13(13.1)$ & $5(4.6)$ & $18(6.2)$ & $36(7.2)$ & .035 \\
\hline
\end{tabular}

Abbreviation: FU, follow-up.

${ }^{a}$ Boldface indicates statistical significance.

upper lumbar spine or whether crossing the thoracolumbar junction provides a biomechanical advantage in long fusion, as evidenced by reoperation rates. Kim et $\mathrm{al}^{5}$ reported no clinical or radiographic significance in reoperation rates between stopping before and after the thoracolumbar junction in 3 groups: T9-T10, T11-T12, and L1-L2 for primary spinal fusions. Reoperation rates in the Kim et $\mathrm{al}^{5}$ study ranged from $24 \%$ to $26 \%$ for fusions with UIVs in the upper lumbar and lower thoracic spine, which is supported by this study's reoperation rates for the UIV thoracic spine $(27 \%)$ and upper lumbar spine (28\%) at last follow-up. The $P$ value of less than .05 for the ANOVA testing on reoperation rates indicates that there exists a significant difference between the UIV groups, but it

Table 6. Cox \& Snell multivariate logistical regression $\left(R^{2}=0.057\right)$ of primary and revision fusions at 2-year follow-up.

\begin{tabular}{|c|c|c|c|c|}
\hline \multirow[b]{2}{*}{ Parameter } & \multirow{2}{*}{$\begin{array}{l}\text { Odds } \\
\text { Ratio }\end{array}$} & \multicolumn{2}{|c|}{$\begin{array}{l}\text { 95\% Confidence } \\
\text { Interval }\end{array}$} & \multirow[b]{2}{*}{$P$ Value } \\
\hline & & Lower & Upper & \\
\hline Revision & 1.328 & 0.718 & 2.455 & .366 \\
\hline Sex & 0.713 & 0.404 & 1.259 & .244 \\
\hline Age & 0.922 & 0.856 & 0.994 & .035 \\
\hline$>50 y$ & 1.082 & 0.192 & 6.088 & .929 \\
\hline$>60 y$ & 2.275 & 0.259 & 19.96 & .458 \\
\hline$>70 y$ & 3.513 & 0.204 & 60.507 & .387 \\
\hline$>80 y$ & 6.527 & 0.171 & 248.592 & .312 \\
\hline $\mathrm{BMI}, \mathrm{kg} / \mathrm{m}^{2}$ & 0.997 & 0.953 & 1.042 & .887 \\
\hline ASA grade & 1.788 & 1.022 & 3.125 & .042 \\
\hline $\mathrm{CCI}$ & 1.136 & 0.915 & 1.41 & .248 \\
\hline T9-T11 to pelvis/sacrum & 1.043 & 0.381 & 2.855 & .934 \\
\hline L1-L2 to pelvis/sacrum & 0.762 & 0.31 & 1.872 & .553 \\
\hline Anterior approach & 1.135 & 0.394 & 3.265 & .815 \\
\hline Posterior approach & 0 & 0 & 0 & .999 \\
\hline Combined approach & 1.051 & 0.295 & 3.747 & .939 \\
\hline TLIF & 1.283 & 0.661 & 2.492 & .461 \\
\hline LLIF/XLIF/OLIF & 1.007 & 0.225 & 4.504 & .993 \\
\hline ALIF & 0.529 & 0.145 & 1.933 & .336 \\
\hline PI-LL mismatch & 0.966 & 0.434 & 2.151 & .933 \\
\hline SVA, cm imbalance C7S1 & 0.673 & 0.237 & 1.912 & .457 \\
\hline
\end{tabular}

Abbreviations: ALIF, anterior lumbar interbody fusion; ASA, American Society of Anesthesiologists; BMI, body mass index; CCI, Charleston Comorbidity Index; LLIF, lateral lumbar interbody fusion; OLIF, oblique lumbar interbody fusion; PI-LL, pelvic incidence-lumbar lordosis; SVA, sagittal vertical axis; TLIF, transforaminal interbody fusion; XLIF, eXtreme lumbar interbody fusion.

${ }^{\mathrm{a} B}$ Boldface indicates statistical significance. does not indicate specifically which group is different from the others. We infer that the statistically significant $P$ value is driven by the lower reoperation rate of the lower lumbar group $(18.2 \%)$, given that the reoperation rates in the thoracic and upper lumbar spine UIV groups are nearly equivalent. This would suggest that there is no obvious advantage or disadvantage to crossing the thoracolumbar junction in long fusion constructs to the sacrum or pelvis. However, patient and surgeon should be aware that the predominant reason for revision differs for lower thoracic UIV (pseudarthrosis and PJK) compared with upper lumbar UIV (adjacent segment disease). The higher rate of PJK in the thoracic UIV group may be explained by the fact that those patients had the highest degree of sagittal imbalance at baseline, as determined by PI-LL. Moreover, the year 1 radiographic data indicate that patients in the thoracic UIV group had the greatest degree of correction in their PI-LL mismatch of almost $12^{\circ}$. Fusion to thoracic spine enables a better correction than UIV in upper lumbar spine. Thus, by choosing the thoracic UIV, one is more likely to get PJK, which is the result of the larger correction. Conversely, if the surgeon chooses a UIV in the upper lumbar spine, one is less likely to get adequate correction and thus more likely to experience higher levels of adjacent segment disease as shown in this study.

The multivariate regression model also suggests that there is no difference in reoperation rates between upper lumbar or thoracic UIV groups. Likewise, there is no difference in reoperation rates between primary or revision cohorts or between different approach types (eg, anterior, posterior, combination). The paper by Kim et $\mathrm{al}^{5}$ referenced earlier did not find statistically significant differences in reoperation rates between upper lumbar and thoracic spine UIV groups. It did not report on 
reoperation rates between primary and revision cohorts or approach type. Pichelmann et $\mathrm{al}^{6}$ did compare revision rates between approaches and found that there was a statistically significant increase in reoperation rates for patients having combined anterior-posterior segmental fusion when compared with anterior or posterior fusion alone. Although this study's findings differ, the discrepancy may be explained by the fact that the anteriorposterior cases in the Pichelmann et $\mathrm{al}^{6}$ study had a higher rate of fusion to the sacrum/pelvis $(51 \%)$, whereas the posterior-only approaches fused to the sacrum/pelvis only $30 \%$ of the time. ${ }^{6}$ Whether or not revision surgeries have higher complication rates is controversial. Basques et $\mathrm{al}^{7}$ examined 14,873 lumbar fusion procedures in the American College of Surgeons National Surgical Quality Improvement Program database and found no differences in the rates of 30-day postoperative complications or readmission between primary and revision posterior lumbar fusion using multivariate analysis to control for patient and operative characteristics. In contrast, Kalakoti et $\mathrm{al}^{8}$ examined 126,044 lumbar fusions in the Nationwide Inpatient Sample during a 9-year period and found that revision surgeries had a higher rate of postoperative complications. ${ }^{8}$ Both studies suffered from a lack of long-term longitudinal follow-up for individual patients within the database and did not look at reoperation rates specifically. Although complication rates and type were not examined in this study, we can conclude that the reoperation rates between primary and revision cohorts did not differ statistically at last follow-up. The regression model did find a statistically significantly decreased probability of reoperation in older patients. Pichelmann et $\mathrm{al}^{6}$ did not find a statistically significant relationship between age and the likelihood of reoperation. Their findings may differ because of the fact that their study focused only on patients with deformity, for which alignment characteristics may have more of an influence on reoperation. Regarding the intraoperative characteristics, this study's findings reflect findings from elsewhere in the literature. Longer constructs had longer operative times, higher rates of blood loss, and longer lengths of stay. So too did constructs with thoracic spine UIV versus upper lumbar spine UIV in the study by Kim et al. ${ }^{9}$

The regression model showed that preoperative sagittal imbalance as determined by PI-LL or C7-S1 sagittal vertical axis (SVA) was not a statistically significant predictor of reoperation. Although only $30 \%$ of the cohort had sagittal parameters measured, this finding is consistent with the results from other studies analyzing preoperative sagittal balance measures and their predictive effect on proximal junctional failure and revision rates. Smith et $\mathrm{al}^{10}$ found that neither the preoperative SVA nor the preoperative PI-LL was a sensitive predictor of acute proximal junctional failure in patients with thoracolumbar fusions. However, in that study postoperative SVA $<5 \mathrm{~cm}$ was a significant predictor of acute proximal junctional failure. Postoperative sagittal balance measurements and their effect on reoperation rates were not a focus of this study and present another area of research to confirm or contradict findings by Smith et al. ${ }^{10}$

A follow-up study that segments patients based on their underlying diagnoses instead of grouping all thoracolumbar fusions into 1 cohort as was done in this study may highlight instances where UIV selection does result in reoperation rate differences; however, it is difficult to achieve statistical power because of the heterogeneity of spinal pathology levels. For example, patients who have degenerative spondylolisthesis and a predisposition to instability may show a higher preponderance for reoperation when constructs stop short of the thoracolumbar junction. Analyzing reoperation rates based on underlying diagnoses is an area for further research.

There are limitations to the study design that could obfuscate the true differences between groups. The choice to use ANOVA testing allowed for the efficient comparison of all 3 UIV groups simultaneously and for the determination that a statistically significant difference between the 3 existed, but it did not allow for the opportunity to determine which particular group or groups were statistically significantly different from the others. Post hoc Tukey analysis allowed for determination of differences between 3 groups (thoracic, upper lumbar, and lower lumbar) with regard to various variables. Further studies can compare each UIV level (L1, L2, and so on) against each other, rather than combining levels into three general groups, as was done in this current study. Given that this study is a retrospective review and not a randomized controlled trial, there may be selection bias such that surgeons chose UIVs in the upper lumbar spine only in patients whom they felt were not likely not to have subsequent complications requiring revision to a higher UIV. Intention to treat cannot be measured when assessing UIV selection 
planning via a retrospective analysis. Another limitation of this study is that there was no analysis of health-related quality-of-life indicators. However, a detailed analysis of the complication associated with each UIV group and the reasons for reoperation was performed, which is equally as important as pain and functional status. There also was not enough data to incorporate a bone health analysis in this study, and bone health is a major driver of PJK and pseudoarthrosis. However, the similar demographic characteristics between the thoracic and upper lumbar UIV groups in terms of age, CCI, and ASA may indicate similar status of bone health between the 2 groups and lend more credence to the comparative analysis. Finally, given that this was a 12-month follow-up study, a longer-term study is warranted to further define outcomes such as pseudoarthrosis, which can take a longer period to be fully characterized.

\section{CONCLUSION}

Constructs with UIV in the thoracic spine experience higher rates of PJK and pseudoarthrosis, whereas those with UIV in the upper lumbar spine have higher rates of adjacent segment disease. Given this tradeoff, there is no certain recommendation on which UIV will result in a lower reoperation rate in thoracolumbar fusion constructs to the sacrum or pelvis. Surgeons must evaluate patient characteristics and risks to make the optimal decision.

\section{ACKNOWLEDGMENTS}

The authors would like to acknowledge the contributions of the following people, who assisted with database updates and chart review: Rivka Ihejirika-Lomedico, MD; Hesham Saleh, MD; Karan Patel, MD; Stephane Owusu-Sarpong, MD; Yixuan Tong; Nicholas O'Malley; Carlos Leon, Carolyn Stickley; Constance Maglaras; and Ethan Ayres.

\section{REFERENCES}

1. Ignasiak D, Peteler T, Fekete TF, Haschtmann D, Ferguson SJ. The influence of spinal fusion length on proximal junction biomechanics: a parametric computational study. Eur Spine J. 2018;27(9):2262-2271. doi:10.1007/s00586-018-5700-3

2. Kim YJ, Bridwell KH, Lenke LG, Rhim S, Cheh G. Sagittal thoracic decompensation following long adult lumbar spinal instrumentation and fusion to L5 or S1: causes, prevalence, and risk factor analysis. Spine (Phila Pa 1976). 2006;31(20):2359-2366. doi:10.1097/01.brs.0000238969.59928. 73
3. Luo M, Wang P, Wang W, Shen M, Xu G, Xia L. Upper thoracic versus lower thoracic as site of upper instrumented vertebrae for long fusion surgery in adult spinal deformity: a meta-analysis of proximal junctional kyphosis. World Neurosurg. 2017;102:200-208. doi:10.1016/j.wneu.2017.02.126

4. Park SJ, Lee CS, Park JS, Lee KJ. Should thoracolumbar junction be always avoided as upper instrumented vertebra in long instrumented fusion for adult spinal deformity?: risk factor analysis for proximal junctional failure. Spine (Phila Pa 1976). 2020;45(10):686-693. doi:10.1097/BRS.0000000000003364

5. Kim YJ, Bridwell KH, Lenke LG, Rhim S, Kim YW. Is the T9, T11, or L1 the more reliable proximal level after adult lumbar or lumbosacral instrumented fusion to L5 or S1? Spine (Phila Pa 1976). 2007;32(24):2653-2661. doi:10.1097/BRS. 0b013e31815a5a9d

6. Pichelmann MA, Lenke LG, Bridwell KH, Good CR, O'Leary PT, Sides BA. Revision rates following primary adult spinal deformity surgery: six hundred forty-three consecutive patients followed-up to twenty-two years postoperative. Spine (Phila Pa 1976). 2010;35(2):219-226. doi:10.1097/BRS. 0b013e3181c91180

7. Basques BA, Fu MC, Buerba RA, Bohl DD, Golinvaux NS, Grauer JN. Using the ACS-NSQIP to identify factors affecting hospital length of stay after elective posterior lumbar fusion. Spine (Phila Pa 1976). 2014;39(6):497-502. doi:10.1097/ BRS.0000000000000184

8. Kalakoti P, Missios S, Maiti T, et al. Inpatient outcomes and postoperative complications after primary versus revision lumbar spinal fusion surgeries for degenerative lumbar disc disease: a national (nationwide) inpatient sample analysis, 20022011. World Neurosurg. 2016;85:114-124. doi:10.1016/j.wneu. 2015.08.020

9. Kim HJ, Boachie-Adjei O, Shaffrey CI, et al. Upper thoracic versus lower thoracic upper instrumented vertebrae endpoints have similar outcomes and complications in adult scoliosis. Spine (Phila Pa 1976). 2014;39(13):E795-E799. doi:10.1097/BRS.0000000000000339

10. Smith MW, Annis P, Lawrence BD, Daubs MD, Brodke DS. Acute proximal junctional failure in patients with preoperative sagittal imbalance. Spine J. 2015;15(10):21422148. doi:10.1016/j.spinee.2015.05.028

Disclosures and COI: No authors of this paper have any pertinent conflicts of interest to disclose.

Corresponding Author: Uchechi Iweala, Email: uaiweala@post.harvard.edu, Phone Number: (202) 642-4292, Mailing Address: Orthopedic Associates of Central Maryland, 910 Frederick Road, Catonsville, Maryland 21228

Published 3 December 2021

This manuscript is generously published free of charge by ISASS, the International Society for the Advancement of Spine Surgery. Copyright (C) 2021 ISASS. To see more or order reprints or permissions, see http://ijssurgery.com. 


\section{APPENDIX}

Table A1. $\quad P$ values for post hoc Tukey comparing age between 3 individual groups.

\begin{tabular}{lccc}
\hline \multicolumn{3}{c}{ Tukey HSD Three Fusion Level for Age } \\
\hline & Thoracic & Upper Lumbar & Lower Lumbar \\
\hline Thoracic & & 0.9910 & 0.0000 \\
Upper lumbar & 0.9910 & & 0.0000 \\
Lower lumbar & 0.0000 & 0.0000 & \\
\hline
\end{tabular}

Abbreviation: HSD, honestly significant difference.

Table A2. $P$ values for post hoc Tukey comparing body mass index (BMI) between 3 individual groups.

\begin{tabular}{lccc}
\hline \multicolumn{3}{c}{ Tukey HSD Three Fusion Level for BMI } \\
\hline & Thoracic & Upper Lumbar & Lower Lumbar \\
\hline $\begin{array}{l}\text { Thoracic } \\
\text { Upper lumbar }\end{array}$ & 0.8670 & 0.8670 & 0.0190 \\
Lower lumbar & 0.0189 & 0.0160 & 0.0160 \\
\hline
\end{tabular}

Abbreviation: HSD, honestly significant difference.

Table A3. $P$ values for post hoc Tukeys comparing American Society of Anesthesiologists (ASA) between 3 individual groups.

\begin{tabular}{lccc}
\hline \multicolumn{4}{c}{ Tukey HSD Three Fusion Level for ASA } \\
\hline & Thoracic & Upper Lumbar & Lower Lumbar \\
\hline $\begin{array}{l}\text { Thoracic } \\
\text { Upper lumbar }\end{array}$ & 0.1820 & 0.1820 & 0.0060 \\
Lower lumbar & 0.0060 & 0.0000 & 0.0000 \\
\hline
\end{tabular}

Abbreviation: HSD, honestly significant difference.

Table A4. $\quad P$ values for post hoc Tukey comparing baseline pelvic incidencelumbar lordosis (PI-LL) between 3 individual groups.

\begin{tabular}{lccc}
\hline \multicolumn{4}{c}{ Tukey HSD Three Fusion Level for baseline PI-LL } \\
\hline & Thoracic & Upper Lumbar & Lower Lumbar \\
\hline $\begin{array}{l}\text { Thoracic } \\
\text { Upper lumbar }\end{array}$ & 0.9140 & 0.9140 & 0.0000 \\
Lower lumbar & 0.0000 & 0.0040 & 0.0040 \\
\hline
\end{tabular}

Abbreviation: HSD, honestly significant difference.

Table A5. $P$ values for post hoc Tukey comparing year 1 pelvic incidencelumbar lordosis (PI-LL) between 3 individual groups.

\begin{tabular}{lccc}
\hline \multicolumn{3}{c}{ Tukey HSD Three Fusion Level for Year 1 PI-LL } \\
\hline & Thoracic & Upper Lumbar & Lower Lumbar \\
\hline $\begin{array}{l}\text { Thoracic } \\
\text { Upper lumbar }\end{array}$ & 0.4600 & 0.0460 & 0.2610 \\
Lower lumbar & 0.2610 & 0.0010 & 0.0010 \\
\hline
\end{tabular}

Abbreviation: HSD, honestly significant difference.
Table A6. Post hoc Tukey for complications between 3 groups. ${ }^{\text {a }}$

\begin{tabular}{|c|c|c|c|c|}
\hline \multicolumn{4}{|c|}{ Complications vs Three Fusion Level } & \multirow[b]{3}{*}{ Total } \\
\hline \multirow[b]{2}{*}{ Complications } & \multicolumn{3}{|c|}{ Three Fusion Level } & \\
\hline & Thoracic & $\begin{array}{c}\text { Upper } \\
\text { Lumbar }\end{array}$ & $\begin{array}{c}\text { Lower } \\
\text { Lumbar }\end{array}$ & \\
\hline \multicolumn{5}{|l|}{ No reoperation } \\
\hline Count & 71 & 41 & 293 & 405 \\
\hline Expected count & 78.6 & 46.5 & 279.9 & 405.0 \\
\hline$\%$ within 2 -y reoperation & 76.3 & 74.5 & 88.5 & 84.6 \\
\hline Adjusted residual & -2.4 & -2.2 & 3.6 & \\
\hline Post hoc probabilities & 0.0164 & 0.0278 & 0.0003 & \\
\hline \multicolumn{5}{|l|}{ Reoperation occurred } \\
\hline Count & 22 & 14 & 38 & 74 \\
\hline Expected count & 14.4 & 8.5 & 51.1 & 74.0 \\
\hline$\%$ within 2 -y reoperation & 23.7 & 25.5 & 11.5 & 15.4 \\
\hline Adjusted residual & 2.4 & 2.2 & -3.6 & \\
\hline Post hoc probabilities & 0.0164 & 0.0278 & 0.0003 & \\
\hline
\end{tabular}

${ }^{a}$ Bonferroni correction of the alpha ( 0.05$)$ divided by the total crosstabulation $(2 \times 3=6)$ is the threshold for statistical significance $(0.05 / 6=0.0083)$ for each post hoc probability listed.

Table A7. Post hoc Tukey for cardiac complications between 3 groups. $^{\text {a }}$

\begin{tabular}{|c|c|c|c|c|}
\hline \multicolumn{4}{|c|}{ Cardiac Complications vs Three Fusion Level } & \multirow[b]{3}{*}{ Total } \\
\hline \multirow[b]{2}{*}{ Cardiac Complications } & \multicolumn{3}{|c|}{ Three Fusion Level } & \\
\hline & Thoracic & $\begin{array}{c}\text { Upper } \\
\text { Lumbar }\end{array}$ & $\begin{array}{l}\text { Lower } \\
\text { Lumbar }\end{array}$ & \\
\hline \multicolumn{5}{|l|}{ No reoperation } \\
\hline Count & 85 & 53 & 326 & 464 \\
\hline Expected count & 89.3 & 53.4 & 321.3 & 464.0 \\
\hline$\%$ within 2 -y reoperation & 92.4 & 96.4 & 98.5 & 97.1 \\
\hline Adjusted residual & -3.0 & -0.3 & 2.8 & \\
\hline Post hoc probabilities & 0.0027 & 0.7642 & 0.0051 & \\
\hline \multicolumn{5}{|l|}{ Reoperation occurred } \\
\hline Count & 7 & 2 & 5 & 14 \\
\hline Expected count & 2.7 & 1.6 & 9.7 & 14.0 \\
\hline$\%$ within 2 -y reoperation & 7.6 & 3.6 & 1.5 & 2.9 \\
\hline Adjusted residual & 3.0 & 0.3 & -2.8 & \\
\hline Post hoc probabilities & 0.0027 & 0.7642 & 0.0051 & \\
\hline
\end{tabular}

${ }^{\mathrm{a}}$ Bonferroni correction of the alpha $(0.05)$ divided by the total crosstabulation $(2 \times 3=6)$ is the threshold for statistical significance $(0.05 / 6=0.0083)$ for each post hoc probability listed.

Table A8. Post hoc for operative time between 3 groups.

\begin{tabular}{lcccc}
\hline & \multicolumn{2}{c}{ Tukey HSD Three Fusion Level } & \\
\cline { 2 - 4 } $\begin{array}{l}\text { Operation } \\
\text { Time (mins) }\end{array}$ & Thoracic & $\begin{array}{c}\text { Upper } \\
\text { Lumbar }\end{array}$ & $\begin{array}{c}\text { Lower } \\
\text { Lumbar }\end{array}$ & Significance \\
\hline 1 & & & 278.71 & 1.00 \\
2 & 444.89 & 391.57 & & 1.00 \\
3 & 90.0 & 54.0 & 324.0 & 1.00 \\
$\mathrm{~N}$ & & & \\
\hline
\end{tabular}

Abbreviations: HSD, honestly significant difference; $\mathrm{N}$, number of parients. 
Table A9. Post hoc Tukey for index procedure being a revision between 3 groups. $^{a}$

\begin{tabular}{|c|c|c|c|c|}
\hline \multicolumn{4}{|c|}{ Revision Index Procedure vs Three Fusion Level } & \multirow[b]{3}{*}{ Tota } \\
\hline \multirow[b]{2}{*}{ Revision Index Procedure } & \multicolumn{3}{|c|}{ Three Fusion Level } & \\
\hline & Thoracic & $\begin{array}{l}\text { Upper } \\
\text { Lumbar }\end{array}$ & $\begin{array}{l}\text { Lower } \\
\text { Lumbar }\end{array}$ & \\
\hline \multicolumn{5}{|l|}{ No reoperation } \\
\hline Count & 41 & 28 & 254 & 323 \\
\hline Expected count & 62.7 & 37.1 & 223.2 & 323.0 \\
\hline$\%$ within 2 -y reoperation & 44.1 & 50.9 & 76.7 & 67.4 \\
\hline Adjusted residual & -5.4 & -2.8 & 6.5 & \\
\hline Post hoc probabilities & 0.0000 & 0.0051 & 0.0000 & \\
\hline \multicolumn{5}{|l|}{ Reoperation occurred } \\
\hline Count & 52 & 27 & 77 & 156 \\
\hline Expected count & 30.3 & 17.9 & 107.8 & 156.0 \\
\hline$\%$ within 2 -y reoperation & 55.9 & 49.1 & 23.3 & 32.6 \\
\hline Adjusted residual & 5.4 & 2.8 & -6.5 & \\
\hline Post hoc probabilities & 0.0000 & 0.0051 & 0.0000 & \\
\hline
\end{tabular}

${ }^{\mathrm{a} B o n f e r r o n i}$ correction of the alpha $(0.05)$ divided by the total crosstabulation $(2 \times 3=6)$ is the threshold for statistical significance $(0.05 / 6=0.0083)$ for each post hoc probability listed.

Table A10. Post hoc Tukey for EBL, $\mathrm{mL}$ between 3 groups.

\section{Tukey HSD Three Fusion Level for EBL}

Group

Thoracic Upper Lumbar Lower Lumbar Significance

1, Thoracic

2, Upper lumbar

3, Lower lumbar 2076.72

$\mathrm{N}$ 87.0

548.91

1.00

1.00

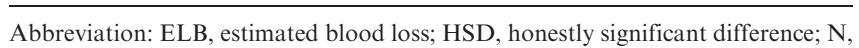
Number of patients.

Table A11. Post hoc Tukey for pelvic fixation between 3 groups. $^{a}$

$$
\text { Pelvic Fixation vs Three Fusion Level }
$$

\begin{tabular}{|c|c|c|c|c|}
\hline \multirow[b]{2}{*}{ Pelvic Fixation } & \multicolumn{3}{|c|}{ Three Fusion Level } & \multirow[b]{2}{*}{ Total } \\
\hline & Thoracic & $\begin{array}{c}\text { Upper } \\
\text { Lumbar }\end{array}$ & $\begin{array}{c}\text { Lower } \\
\text { Lumbar }\end{array}$ & \\
\hline \multicolumn{5}{|l|}{ No reoperation } \\
\hline Count & 45 & 41 & 320 & 406 \\
\hline Expected count & 78.8 & 46.6 & 280.6 & 406.0 \\
\hline$\%$ within 2 -y reoperation & 48.4 & 74.5 & 96.7 & 84.8 \\
\hline Adjusted residual & -10.9 & -2.2 & 10.9 & \\
\hline Post hoc probabilities & 0.0000 & 0.0278 & 0.0000 & \\
\hline \multicolumn{5}{|l|}{ Reoperation occurred } \\
\hline Count & 48 & 14 & 11 & 73 \\
\hline Expected count & 14.2 & 8.4 & 50.4 & 73.0 \\
\hline$\%$ within 2 -y reoperation & 51.6 & 25.5 & 3.3 & 15.2 \\
\hline Adjusted residual & 10.9 & 2.2 & -10.9 & \\
\hline Post hoc probabilities & 0.0000 & 0.0278 & 0.0000 & \\
\hline
\end{tabular}

${ }^{\mathrm{a} B o n f e r r o n i}$ correction of the alpha $(0.05)$ divided by the total crosstabulation $(2 \times 3=6)$ is the threshold for statistical significance $(0.05 / 6=0.0083)$ for each post hoc probability listed.

Table A12. Post hoc Tukey for length of stay, days between 3 groups.

\begin{tabular}{|c|c|c|c|c|}
\hline \multirow[b]{2}{*}{ Group } & \multicolumn{4}{|c|}{ Tukey HSD Three Fusion Level for LOS } \\
\hline & Thoracic & Upper Lumbar & Lower Lumbar & Significance \\
\hline \multirow{4}{*}{$\begin{array}{l}\text { 1, Thoracic } \\
\text { 2, Upper lumbar } \\
\text { 3, Lower lumbar } \\
\mathrm{N}\end{array}$} & & & 7.6966 & 1.00 \\
\hline & & 6.2407 & & 1.00 \\
\hline & 4.0004 & & & 1.00 \\
\hline & 89.0 & 54.0 & 324.0 & \\
\hline
\end{tabular}

Abbreviation: HSD, honestly significant difference; LOS, length of stay; N, number of patients.
Table A13. Post hoc Tukey for reoperation at last follow-up between 3 groups. ${ }^{\text {a }}$ Reoperation at Last Follow-up vs Three Fusion Level

\begin{tabular}{|c|c|c|c|c|}
\hline \multirow[b]{2}{*}{$\begin{array}{l}\text { Reoperation at } \\
\text { Last Follow-up }\end{array}$} & \multicolumn{3}{|c|}{ Three Fusion Level } & \multirow[b]{2}{*}{ Total } \\
\hline & Thoracic & $\begin{array}{c}\text { Upper } \\
\text { Lumbar }\end{array}$ & $\begin{array}{l}\text { Lower } \\
\text { Lumbar }\end{array}$ & \\
\hline \multicolumn{5}{|l|}{ No reoperation } \\
\hline Count & 67 & 40 & 273 & 380 \\
\hline Expected count & 73.8 & 43.6 & 262.6 & 380.0 \\
\hline$\%$ within 2 -y reoperation & 72.0 & 72.7 & 82.5 & 79.3 \\
\hline Adjusted residual & -1.9 & -1.3 & 2.5 & \\
\hline Post hoc probabilities & 0.0574 & 0.1936 & 0.0124 & \\
\hline \multicolumn{5}{|l|}{ Reoperation occurred } \\
\hline Count & 26 & 15 & 58 & 99 \\
\hline Expected count & 19.2 & 11.4 & 68.4 & 99.0 \\
\hline$\%$ within 2 -y reoperation & 28.0 & 27.3 & 17.5 & 20.7 \\
\hline Adjusted residual & 1.9 & 1.2 & -2.5 & \\
\hline Post hoc probabilities & 0.0574 & 0.2301 & 0.0124 & \\
\hline
\end{tabular}

${ }^{a}$ Bonferroni correction of the alpha $(0.05)$ divided by the total crosstabulation $(2 \times 3=6)$ is the threshold for statistical significance $(0.05 / 6=0.0083)$ for each post hoc probability listed.

Table A14. Post hoc Tukey for reoperation for adjacent segment disease between 3 groups. ${ }^{\text {a }}$

\begin{tabular}{|c|c|c|c|c|}
\hline \multicolumn{4}{|c|}{ Reoperation for Adjacent Segment Disease vs Three Fusion Level } & \multirow[b]{3}{*}{ Total } \\
\hline \multirow[b]{2}{*}{$\begin{array}{l}\text { Reoperation for Adjacent } \\
\text { Segment Disease }\end{array}$} & \multicolumn{3}{|c|}{ Three Fusion Level } & \\
\hline & Thoracic & $\begin{array}{c}\text { Upper } \\
\text { Lumbar }\end{array}$ & $\begin{array}{l}\text { Lower } \\
\text { Lumbar }\end{array}$ & \\
\hline \multicolumn{5}{|l|}{ No reoperation } \\
\hline Count & 92 & 50 & 314 & 456 \\
\hline Expected count & 88.5 & 52.4 & 315.1 & 456.0 \\
\hline$\%$ within 2 -y reoperation & 98.9 & 90.9 & 94.9 & 95.2 \\
\hline Adjusted residual & 1.9 & -1.6 & -0.5 & \\
\hline Post hoc probabilities & 0.0574 & 0.1096 & 0.6171 & \\
\hline \multicolumn{5}{|l|}{ Reoperation occurred } \\
\hline Count & 1 & 5 & 17 & 23 \\
\hline Expected count & 4.5 & 2.6 & 15.9 & 23.0 \\
\hline$\%$ within 2 -y reopening & 1.1 & 9.1 & 5.1 & 4.8 \\
\hline Adjusted residual & -1.9 & 1.6 & 0.5 & \\
\hline Post hoc probabilities & 0.0574 & 0.1096 & 0.6171 & \\
\hline
\end{tabular}

${ }^{a}$ Bonferroni correction of the alpha $(0.05)$ divided by the total crosstabulation $(2 \times 3=6)$ is the threshold for statistical significance $(0.05 / 6=0.0083)$ for each post hoc probability listed.

Table A15. Post hoc Tukey for reoperation for pseudoarthrosis between 3 groups. $^{a}$

\begin{tabular}{|c|c|c|c|c|}
\hline \multicolumn{4}{|c|}{ Reoperation for Pseudoarthrosis vs Three Fusion Level } & \multirow[b]{3}{*}{ Total } \\
\hline \multirow[b]{2}{*}{$\begin{array}{l}\text { Reoperation for } \\
\text { Pseudoarthrosis }\end{array}$} & \multicolumn{3}{|c|}{ Three Fusion Level } & \\
\hline & Thoracic & $\begin{array}{c}\text { Upper } \\
\text { Lumbar }\end{array}$ & $\begin{array}{c}\text { Lower } \\
\text { Lumbar }\end{array}$ & \\
\hline \multicolumn{5}{|l|}{ No reoperation } \\
\hline Count & 80 & 52 & 313 & 445 \\
\hline Expected count & 86.4 & 51.1 & 307.5 & 445.0 \\
\hline$\%$ within 2 -y reoperation & 86.0 & 94.5 & 94.6 & 92.9 \\
\hline Adjusted residual & -2.9 & 0.5 & 2.1 & \\
\hline Post hoc probabilities & 0.0037 & 0.6171 & 0.0357 & \\
\hline \multicolumn{5}{|l|}{ Reoperation occurred } \\
\hline Count & 13 & 3 & 18 & 34 \\
\hline Expected count & 6.6 & 3.9 & 23.5 & 34.0 \\
\hline$\%$ within 2 -y reoperation & 14.0 & 5.5 & 5.4 & 7.1 \\
\hline Adjusted residual & 2.9 & -0.5 & -2.1 & \\
\hline Post hoc probabilities & 0.0037 & 0.6171 & 0.0357 & \\
\hline
\end{tabular}

${ }^{\text {a } B o n f e r r o n i ~ c o r r e c t i o n ~ o f ~ t h e ~ a l p h a ~}(0.05)$ divided by the total crosstabulation $(2 \times 3=6)$ is the threshold for statistical significance $(0.05 / 6=0.0083)$ for each post hoc probability listed. 